\title{
Synthesis and Characterization of New Meso-Substituted and $\beta$-Substituted Unsymmetrical Metalloporphyrins
}

\author{
GAURI D BAJJU*, NARINDER SINGH and DEEPMALA \\ Department of Chemistry University of Jammu, Jammu-18006, India \\ gauribajju@gmail.com
}

Received 9 March 2013 / Accepted 30 April 2013

\begin{abstract}
The synthesis and characterization of new meso-substituted and $\beta$-substituted unsymmetrical metallorphyrins has been described. A new modified Alder method was used for the synthesis of unsymmetrical porphyrins. Reaction of these unsymmetrical porphyrins with metal chlorides and nitrates afforded the corresponding metalloporphyrins in high yields with excellent purity. These porphyrins and their metal derivatives were characterized by spectroscopic methods.
\end{abstract}

Keywords: Meso-functionalization, Unsymmetrical metalloporphyrins, Metal ligand interaction

\section{Introduction}

Porphyrins are unique class of compounds with potential applications in all disciplines of Science, including medicine ${ }^{1}$. The electronic properties of porphyrins can be changed by introducing suitable substituents at the meso-position or $\beta$-position. Porphyrins and metallophyrins are essential to the life of bacteria, fungi, plants and animals and have received considerable attention from many investigators in various fields. Synthetic porphyrins, especially meso-tetraphenyl porphyrin derivatives substituted in the paraposition with soluble acidic, basic and neutral groups are of potential interest in medicinal chemistry because they can form chelates either with some toxic heavy metals or with a gamma-ray emitting radioisotopes ${ }^{2-4}$.

Although some degree of control may be achieved by altering the substitutents on the aryl rings of meso-tetraarylporphyrins ${ }^{5}$, large changes in redox properties may be achieved by direct substitution on the porphyrin macrocycle ${ }^{6}$. The position and the nature of the substituents on the porphyrins considerably alter the planar structure of these entities and confer certain unique spectroscopic properties ${ }^{7}$. Among various peripheral substituents, nitro group was shown to have major effect in spectral and electrochemical behaviour of the porphyrins $^{8}$. Although substitution at this position is impossible for meso-tetraaryl porphyrins, nitration of tetraphenylporphyrin at the pyrrole $\beta$-position is facile ${ }^{9}$ and the resulting mono nitro product is a better electron acceptor than meso-tetraphenylporphyrin itself by $\sim 350 \mathrm{mV}$. Several interesting studies of porphyrins endowed with nitro groups either 
at the $\beta$-pyrrole positions or directly attached at the meso carbon atoms ${ }^{10}$ or on the meso-aryl rings ${ }^{11}$ have been reported in the literature. A systematic spectroscopic studies of the mesofluoroarylporphyrins with different peripheral substituents would be of great interest to elucidate the effect of substituents on the display of many spectral properties. The better solubility of these porphyrins in a wide variety of solvents, higher chemical stability owing to the steric effect of the fluorine atoms and non-aggregation properties of tetra(pentafluoro) phenylporphyrin make them an attractive system to study ${ }^{12}$. These porphyrins exhibit catalytic activity towards hydrocarbon oxygenation reactions ${ }^{13}$. Metal complexes of tetrapyrrolic macrocycles play a key role with respect to life on earth because of their implications in a variety of enzymatic systems ${ }^{14}$. Their ability to carry out the reactions rather unusual in organic chemistry has been the object of intensive investigations aiming to utilize them as a model compounds for biological systems and as catalyst ${ }^{15}$. Therefore the synthesis of well defined meso-substituted unsymmetrical porphyrin derivatives is of great interest for development of new unsymmetrical porphyrins were synthesized using modified Alder method ${ }^{16}$.

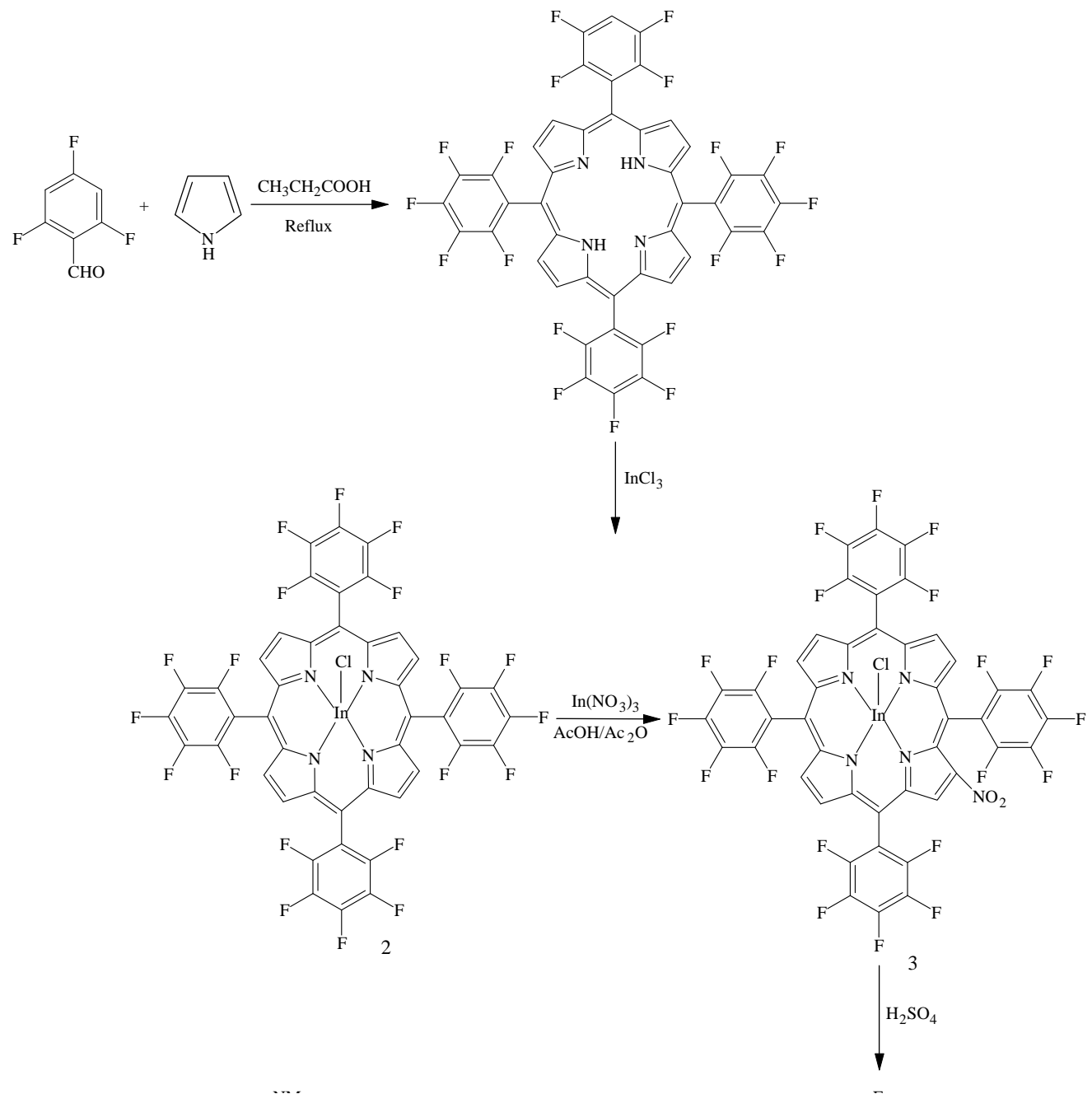




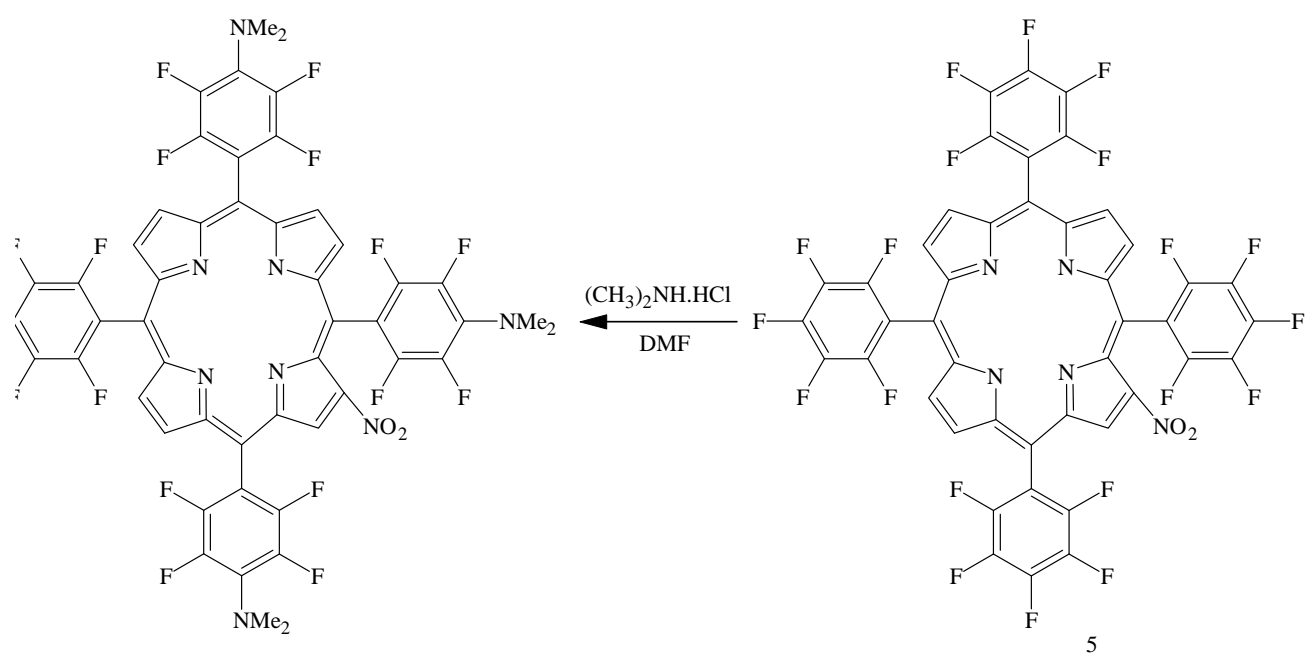

Scheme 1. Synthetic route for substituted porphyrin and metalloporphyrin

We report here convenient synthesis of some metalloporphyrins using meso-substituted unsymmetrical porphyrins.

\section{Experimental}

The pyrrole and propionic acid were distilled before use. The IR spectra were recorded on Shimadzu infrared spectrophotometer (FT-IR-8400). The NMR spectra were recorded on using tetramethyl silane as internal standard. UV-Visible spectra were obtained on Shimadzu UV-spectrometer using chloroform. Mass spectra were obtained on micromass (Q-T of micro YA-105) using chloroform Elemental analysis was carried out on Perkin Elmer elemental analyzer. Synthesis of tetrakis(pentafluoro)phenyl porphyrin $\left(\mathrm{H}_{2} \mathrm{TFPPa}\right)$ were prepared using modified Alder method ${ }^{16}$.

Synthesis of tetrakis (2,3,5,6-tetrafluoro-4-dimethylamino) phenylprophyrin $\left(\mathrm{H}_{2} \mathrm{TFPPb}\right)$ In a $100 \mathrm{~mL}$ round bottom flask $130 \mathrm{mg}(0.13 \mathrm{mmol})$ of $\mathrm{H}_{2}$ TFPPa was dissolved in $40 \mathrm{~mL}$ of distilled DMF and $3.2 \mathrm{~g}$ of dimethylammonium chloride 39 (mmol) was added to it. The resulting solution was refluxed under $\mathrm{N}_{2}$ for 15 hours. The solvent was removed under reduced pressure the crude solid product was dissolved in $\mathrm{CHCl}_{3}$ and washed several times with distilled water to remove excess amine. The chloroform extract was purified by silica gel column chromatography with $\mathrm{CHCl}_{3}$ :pet. ether $(1: 1, \mathrm{v} / \mathrm{v})$ mixture as eluant. The first fraction was discarded and the second reddish brown colour fraction was collected as the desired product. The yield of the product was $90 \%$ based on starting porphyrin $\left(\mathrm{H}_{2} \mathrm{TFPPa}\right)$. The compound was characterized by ${ }^{1} \mathrm{H}$ and ${ }^{19} \mathrm{~F}$ NMR spectroscopies. FAB-MS showed molecular ion peak $(\mathrm{m} / \mathrm{z})$ at $1075(\mathrm{M}+\mathrm{H})^{+}\left(\right.$Calc. $\mathrm{M}^{+}$. for $\left.\mathrm{C}_{52} \mathrm{H}_{34} \mathrm{~N}_{8} \mathrm{~F}_{16}=1074\right)$.

Synthesis of 2-nitro $(5,10,15,20)$ tetrakis (pentafluoro)phenylporphyrin $\left(\mathrm{H}_{2} \mathrm{TFPPC}\right)$

In $160 \mathrm{~mL}$ of $\mathrm{CHCl}_{3}$ InTFPPa (250 mg) was dissolved and $\mathrm{In}\left(\mathrm{NO}_{3}\right)_{3} \cdot \mathrm{H}_{2} \mathrm{O}(116 \mathrm{mg})$ in $25 \mathrm{~mL}$ mixture of acetic anhydride and acetic acid (4:1, v/v) was added to it. The reaction mixture was stirred at $40{ }^{\circ} \mathrm{C}$ for 30 hours. At the end of the reaction, the solution was neutralized with aqueous $\mathrm{Na}_{2} \mathrm{CO}_{3}$ solution and the $\mathrm{CHCl}_{3}$ was subjected to silica gel column chromatorgrphy to obtain the pure product. 
Initially eluant used was (3:1, v/v) mixture of pet.ether and chloroform to remove all unreacted InTFPPa and then eluant was changed to $(3: 2, \mathrm{v} / \mathrm{v})$ product. Increasing the $\mathrm{HCCl}_{3}$ in the eluant mixture helps in the separation of higher nitro derivatives. The free base porphyrin ( $\mathrm{H}_{2}$ TFPPc) was obtained by acid demetallation of InTFPPc with $\mathrm{H}_{2} \mathrm{SO}_{4}$ following standard procedure. The overall yield of the desired product was $50 \%$ based on starting porphyrin (InTFPPc). The compound was characterized by UV-Vis. ${ }^{1} \mathrm{H}$ and ${ }^{19} \mathrm{~F}-\mathrm{NMR}$ spectroscopies. FAB-MS showed molecular ion peak $(m / z)$ at $1020(\mathrm{M}+\mathrm{H})^{+}$. (Calc. $\mathrm{M}+$. for $\left.\mathrm{C}_{44} \mathrm{H}_{9} \mathrm{~F}_{20} \mathrm{O}_{2}=1019\right)$.

Synthesis of 2-nitro $(5,10,15,20)$ tetrakis $(2,3,5,6$-tetrafluoro-4-dimethylamino)phenyl porphyrin ( $\left.\mathrm{H}_{2} \mathrm{TFPPd}\right)$

In a $100 \mathrm{~mL}$ round bottom flask $\mathrm{H}_{2}$ TFPPc $(120 \mathrm{mg}, 0.12 \mathrm{mmol})$ was dissolved in distilled DMF (40 mL) and dimethyl ammonium chloride (3.0 g, $37 \mathrm{mmol}$ ) was added to it. The resulting solution was refluxed under $\mathrm{N}_{2}$ for $15 \mathrm{~h}$. At the end of the reaction, the solvent was removed under reduced pressure, the solid crude product was dissolved in $\mathrm{CHCl}_{3}$ and washed several times with distilled water to remove the excess amine. The $\mathrm{CHCl}_{3}$ extract was dried over anhydrous $\mathrm{Na}_{2} \mathrm{SO}_{4}$ and the solution was then concentrated and passed through silica gel column. On elution with $\mathrm{CHCl}_{3}$, the most intense brown band after yellowish orange fraction was collected as the desired product. The yield of the product was $75 \%$ based on starting porphyrin ( $\mathrm{H}_{2}$ TFPPc).The compound was characterized by UV-Visible, ${ }^{1} \mathrm{H}$ and ${ }^{19} \mathrm{~F}$ NMR spectroscopies. FAB-MS showed molecular ion peak $(\mathrm{m} / \mathrm{z})$ at $1120(\mathrm{M}+\mathrm{H})^{+}$(calc. $\mathrm{M}+$. for $\mathrm{C}_{44} \mathrm{H}_{9} \mathrm{~N}_{5} \mathrm{~F}_{20} \mathrm{O}_{2}-1119$ ).

\section{Synthesis of In(III) derivatives of the porphyrins}

The In(III) derivatives of the unsubstituted and substituted fluoroarylporphyrin were prepared using the In(III)chloride as the carrier. A typical procedure for the synthesis of InTFPPd is as follows; To a solution of free-base $\left(\mathrm{H}_{2}\right.$ TFPPd) porphyrin $(100 \mathrm{mg}, 0.09 \mathrm{mmol})$ in $25 \mathrm{~mL}$ of $\mathrm{CHCl}_{3}$ excess of $\mathrm{In}(\mathrm{III})$ chloride $(200 \mathrm{mg}$ ) in $15 \mathrm{~mL}$ of methanol was added and the reaction mixture was refluxed for a period of $30 \mathrm{~min}$. Then the solvent was evaporated under reduced pressure and the residue thus obtained was washed with water and extracted in $\mathrm{CHCl}_{3}$ and dried over anhydrous $\mathrm{Na}_{2} \mathrm{SO}_{4}$. The resultant $\mathrm{CHCl}_{3}$ solution was chromatographed on a silica gel column using $\mathrm{CHCl}_{3}$ as the eluant. The yield of the product was found to be greater than $90 \%$. In all the cases compounds were characterized by UV-Vis, ${ }^{1} \mathrm{H}$ and ${ }^{19} \mathrm{~F}$ NMR spectroscopies and purity of the samples were verified by thin layer chromatography.

\section{Results and Discussion}

Nitration of the $\mathrm{H}_{2}$ TFPP can in principle lead to polynitrated products. We achieved the preparation of $\beta$-mononitro tetrakis (pentafluorophenyl)porphyrin (InTFPPc) by nitration of the In(III) derivative of tetrakis (pentafluorophenyl) porphyrin (InTFPPa) by $\operatorname{In}\left(\mathrm{NO}_{3}\right)_{3} \cdot \mathrm{H}_{2} \mathrm{O}$. The isolated yield of mono nitro substituted product compared to other higher nitro derivatives are highly dependent on the ratio of the porphyrinato $\operatorname{In}\left(\mathrm{NO}_{3}\right)_{3}$ and the reaction time at a given temperature. In general a mixture of mono, di and tri nitro compounds were obtained in such reactions. We obtained InTFPP( $\mathrm{NO}_{2}$ ) (InTFPPc) in 50\% yield by using optimum conditions. The $\mathrm{N}, \mathrm{N}$-dimethylamino groups were introduced into the mesofluoroaryl rings by nucleophilic substitution of para fluorine atoms by $-\mathrm{NMe}_{2}$ group.

\section{${ }^{1} \mathrm{H}$ and ${ }^{19} \mathrm{~F}$ NMR spectroscopy}

The NMR spectra of the free-base porphyrins and their In(III) derivatives are highly characteristic and provides structural information of these compounds in solution. The ${ }^{1} \mathrm{H}$ NMR data is given the Table 1 . The integrated intensity of the resonance agree well with the number 
of protons. The assignment of various resonances were carried out by comparison with the ${ }^{1} \mathrm{H}$ NMR spectra of $\mathrm{H}_{2}$ TFPP and InTFPP. The inner imino proton resonance of the unsubstituted porphyrin, $\mathrm{H}_{2}$ TFPPa undergo a downfield shift on incorporation of electron donating/withdrawing groups $-\mathrm{N}\left(\mathrm{CH}_{3}\right)_{2}$ and nitrogroup in the mesofluoraryl rings and one of the pyrrole carbons of the tetrapyrrole moiety respectively. The shift is found to be maximum when both donor and acceptor groups are present in the porphyrin $\left(\mathrm{H}_{2} \mathrm{TFPPd}\right)$. This suggests a change in the electron density on the inner imino nitrogens as a consequence of substitution of the different groups in the peripheral positions of the porphyrins. However, the presence of $-\mathrm{NMe}_{2}$ groups in the meso-fluoroaryl rings appear to have less influence in the shift of the imino proton resonances compared to that produced by the $-\mathrm{NMe}_{2}$ groups on the meso-tetraphenyl porphyrin. Interestingly, the proton resonance of $-\mathrm{N}\left(\mathrm{CH}_{3}\right)_{2}$ groups in $\mathrm{H}_{2} \mathrm{TFPPb}$ appear as a triplet in contrast to a singlet resonance in the corresponding mesotetraphenyl porphyrins. The occurrence of a triplet resonance is ascribed to the coupling between the m-fluorine atoms of meso-fluoroaryl ring and the protons of $-\mathrm{N}\left(\mathrm{CH}_{3}\right)_{2}$ group. The major effect of nitro group substitutions in the exhibition of a multiplet resonance for pyrrole protons. The seven $\beta$-pyrrole proton resonances of $\mathrm{H}_{2}$ TFPPc are classified easily from the integrated intensity pattern. Thus the singlet at $9.15 \mathrm{ppm}$ is assigned to the proton juxtapositioned to the nitro group of the same pyrrole ring (ring I) and the broad signal at $9.02 \mathrm{ppm}$ is assigned to the four protons belonging to the two pyrrole rings positioned on either side of the pyrrole ring bearing the nitro group (ring II and IV). The relatively higher upfield shifted resonance centred at $8.79 \mathrm{ppm}$ is assigned to the protons of the pyrrole ring positioned diagonally opposite to the pyrrole ring bearing the nitro group (ring III). The presence of $-\mathrm{N}\left(\mathrm{CH}_{3}\right)_{2}$ groups in the meso-fluoroaryl rings of the porphyrin, $\mathrm{H}_{2} \mathrm{TFPPd}$ retains the pattern of the pyrrole proton resonances as in $\mathrm{H}_{2}$ TFPPc. The proton resonances of $-\mathrm{N}\left(\mathrm{CH}_{3}\right)$ groups in $\mathrm{H}_{2} \mathrm{TFPPd}$, However, appear as a multiplet (instead of a triplet as in $\mathrm{H}_{2} \mathrm{TFPPb}$ ) indicating partial rotation of the fluoroaryl rings to different extent. The presence of In(III) in the porphyrins result in the shift of the resonances to low field accompanied by the change in splitting pattern of the resonances indicating conformational change of the porphyrin core.

Table 1. ${ }^{1} \mathrm{H} \mathrm{NMR}^{\mathrm{a}}$ data ( $\delta$ in ppm) of the porphyrins in $\mathrm{CDCl}_{3}$ at $300 \mathrm{~K}$

\begin{tabular}{cccc}
\hline Compound & $\beta-\mathrm{H}$ & $-\mathrm{NMe}_{2}-\mathrm{H}$ & $-\mathrm{NH}$ \\
\hline $\mathrm{H}_{2}$ TFPPa & $8.92(\mathrm{~s})$ & - & $-2.92(\mathrm{~s})$ \\
$\mathrm{H}_{2}$ TFPPb & $8.94(\mathrm{~s})$ & $3.28(\mathrm{t})$ & $-2.86(\mathrm{~s})$ \\
& $9.15(\mathrm{~s})$ & & \\
$\mathrm{H}_{2}$ TFPPc & $9.02(\mathrm{~b})$ & - & $-2.83(\mathrm{~s})$ \\
& $8.79(\mathrm{~d} / \mathrm{d})$ & & \\
& $9.17(\mathrm{~s})$ & & \\
$\mathrm{H}_{2}$ TFPPd & $9.03(\mathrm{q})$ & $3.28(\mathrm{~m})$ & $-2.75(\mathrm{~s})$ \\
& $8.80(\mathrm{~s})$ & & - \\
InTFPPa & $9.01(\mathrm{~s})$ & - & - \\
InTFPPb & $9.03(\mathrm{~s})$ & $3.28(\mathrm{t})$ & - \\
InTFPPc & $9.25(\mathrm{~s})$ & - & \\
& $8.94(\mathrm{~m})$ & & \\
InTFPPd & $9.28(\mathrm{~s})$ & $3.28(\mathrm{~m})$ & \\
\hline
\end{tabular}

$a{ }^{1} H$ NMR values are versus TMS at 0 ppm; $d / d=$ doublet of doublet, $d=$ doublet; $S=$ singlet; $q=$ quartet $; m=$ multiple; $t=$ triplet 
Fluorine -19 NMR ha been extremely helpful in ascertaining both the identity and purity of the compound. The $100 \%$ natural abundance of spin $1 / 2{ }^{19} \mathrm{~F}$ and its high gyromagnetic ratio allow ${ }^{19} \mathrm{~F}$ NMR spectra to be obtained readily. The ${ }^{19} \mathrm{~F}$ NMR spectra are usually first order in their multiplicities and this permits detailed structural analysis to be made from the observed splitting patterns. The fluorine atoms of all four phenyl groups appear equivalent in ${ }^{19} \mathrm{~F}$-NMR spectrum as $o$-, $m$ - and $p$-fluorine atoms. The four meso-fluoroaryl rings on the porphyrin are related to high degree of symmetry. The chemical shift of the fluorine atoms on the meso fluoroaryl rings are extremely sensitive to the metal centres its meso-aryl and the pyrrole carbon atom substituents. The resonances of fluorine atoms of the meso-aryl rings occur at characteristic frequencies and are easily distinguishable from the position and nature of the multiplet of the resonance and their integrated intensities. The incorporation of $-\mathrm{N}\left(\mathrm{CH}_{3}\right)_{2}$ group in the $p$-position of the meso-fluoroaryl rings shift the $o$-and $m$ - fluorine resonances up field and downfiled respectively by about 4.0 and $9.0 \mathrm{ppm}$ while the $-\mathrm{NO}_{2}$ group substitution at the $\beta$-pyrrole carbon doesnot shift the ${ }^{19} \mathrm{~F}$ resonances significantly. Interestingly, the fluorine atoms in the nitroporphyrins are easily distinguishable depending upon the location of $-\mathrm{NO}_{2}$ group in the pyrrole ring. The $o$-fluorine atom resonances in $\mathrm{H}_{2}$ TFPPc appear as three closely spaced doubled of doublets while these resonances appear unresolved in $\mathrm{H}_{2}$ TFPPa and $\mathrm{H}_{2}$ TFPPb. The resonances at $-137.5 \mathrm{ppm}$, arise from the $o$-fluorine atoms of the fluoroaryl ring at $\mathrm{C}_{15}$ and the peak centred at $-136.7 \mathrm{ppm}$ was ascribed to the fluorine atoms of the fluoroaryl rings adjacent to the pyrrole ring bearing the nitro group (at $\mathrm{C}_{10}$ and $\mathrm{C}_{20}$ ). The most downfield shifted peak at $-136.4 \mathrm{ppm}$ was assigned to the fluorine atoms of the phenyl ring adjacent to the nitro group (at $\left.\mathrm{C}_{5}\right)$. A similar splitting pattern was also observed for the $\mathrm{m}$-fluorine atoms. The single set of triplet that appeared for the p-fluorine atoms of meso-fluoroaryl rings of the porphyrin $\left(\mathrm{H}_{2} \mathrm{TFPPa}\right)$, split into two multiplets in nitro substituted porphyrin $\left(\mathrm{H}_{2} \mathrm{TFPPc}\right)$ due to the $\mathrm{p}$-fluorine atoms of neighbouring and distant meso-fluoroaryl rings. A marginal change was observed in the ${ }^{19} \mathrm{~F}$ NMR spectra of the porphyrins upon In(III) ion incorporation.

Table 2. ${ }^{19} \mathrm{~F}-\mathrm{NMR}^{\mathrm{a}}$ data ( $\delta$ in ppm) of the porphyrin in $\mathrm{CDCl}_{3}$ at $300 \mathrm{~K}$

\begin{tabular}{cccc}
\hline Compound & ortho & meta & Para \\
\hline $\mathrm{H}_{2}$ TFPPa & $-136.8(\mathrm{~d})$ & $-161.5(\mathrm{t})$ & $-151.5(\mathrm{t})$ \\
$\mathrm{H}_{2}$ TFPPb & $-140.4(\mathrm{~d} / \mathrm{d})$ & $-152.5(\mathrm{~d})$ & - \\
& $-136.4(\mathrm{~d} / \mathrm{d})$ & $-160.6(\mathrm{~m})$ & $-149.7(\mathrm{~m})$ \\
$\mathrm{H}_{2}$ TFPPC & $-136.7(\mathrm{~d} / \mathrm{d})$ & $-160.9(\mathrm{~m})$ & $-150.5(\mathrm{~m})$ \\
& $-137.5(\mathrm{~d} / \mathrm{d})$ & $-161.2(\mathrm{~m})$ & - \\
& $-140.2(\mathrm{~d} / \mathrm{d})$ & $-151.9(\mathrm{bd})$ & - \\
$\mathrm{H}_{2}$ TFPPd & $-140.4(\mathrm{~d} / \mathrm{d})$ & $-152.2(\mathrm{bd})$ & - \\
& $-141.3(\mathrm{~d} / \mathrm{d})$ & $-152.7(\mathrm{bd})$ & - \\
InTFPPa & $-138.5(\mathrm{~d})$ & $-163.7(\mathrm{~m})$ & $-154.8(\mathrm{t})$ \\
InTFPPb & $-140.4(\mathrm{~d} / \mathrm{d})$ & $-152.5 \mathrm{~d}$ & - \\
& $-136.7(\mathrm{~d} / \mathrm{d})$ & $-161.1(\mathrm{~m})$ & $-150.7(\mathrm{~m})$ \\
InTFPPc & $-136.9(\mathrm{~d} / \mathrm{d})$ & $-161.5(\mathrm{~m})$ & $-151.4(\mathrm{t})$ \\
& $-137.7(\mathrm{~d} / \mathrm{d})$ & $-161.9(\mathrm{~m})$ & - \\
InTFPPd & $-140.5(\mathrm{~d})$ & $-152.1(\mathrm{~d})$ & - \\
& $-141.3(\mathrm{~d})$ & $-153.4(\mathrm{~d})$ & - \\
& & $-152.9(\mathrm{~d})$ & -
\end{tabular}

${ }^{a 19} \mathrm{~F}$ NMR values are versus $\mathrm{CFCl}_{3}$ at 0 ppm. $d / d=$ doublet; $d=$ doublet; $s=$ singlet $q=$ quartet; $m=$ multiplet; $t=$ triplet 


\section{Electrochemical redox properties}

The electrochemical redox properties of the porphyrins and their metallated derivatives arise primarily from the $\pi$-electron system of the macrocycle. Cyclic voltametric and differential pulse voltammetric studies have been carried out for all the synthesized free-base fluoroarylporphyrins and their metal derivatives [Indium(III)] to elucidate the effect of peripheral substitutents at pyrrole position and meso-fluoroaryl rings on the electrochemical redox potentials. The electrochemical redox date of the synthesized compounds in $\mathrm{CH}_{2} \mathrm{Cl}_{2}$ solution are given in Table 3. In most of the cases only first oxidation process was observed because the second ring oxidation occurs at a potential too close to the solvent oxidation. It is seen that the presence of fluoroaryl groups at the meso-position of the porphyrin shifts the ring oxidation and reductions to a more anodic potential relative to that found for tetraphenyl porphyrins. The free-base fluoroarylporphyrins $\left(\mathrm{H}_{2} \mathrm{TFPPa}\right)$ and its Indium (III) derivatives exhibit one electron ring oxidation to a more anodic potential relative to that found for mesotetraphenylporphyrin and its metal(III) derivatives. This suggests the highly electron deficient nature of pentafluoroaryl porphyrins relative to the corresponding mesotetraphenylporphyrins.

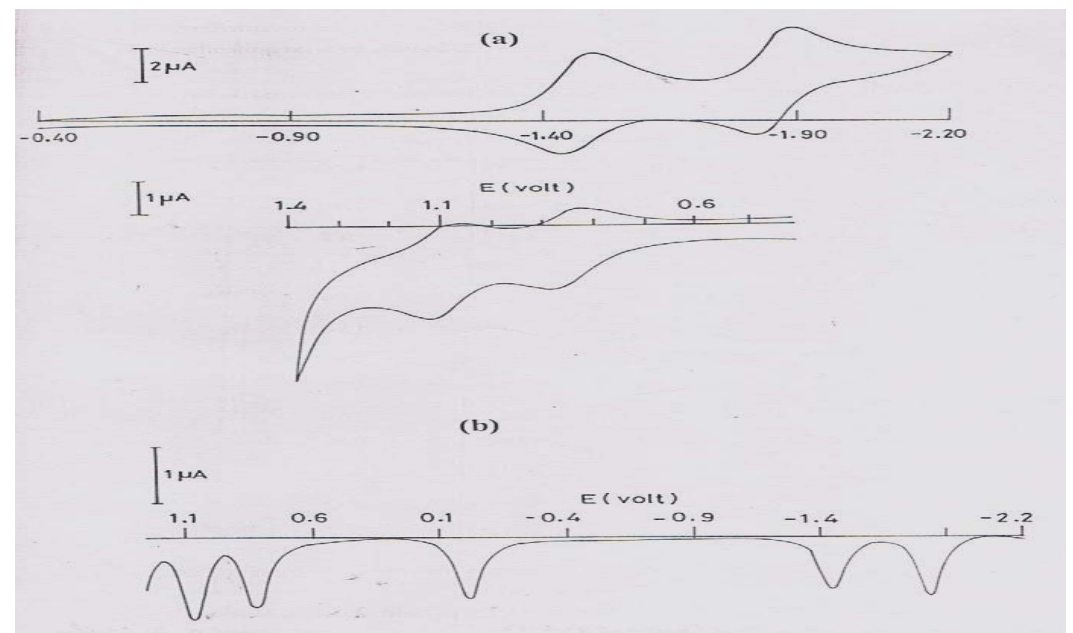

Figure 1 (a). Cyclic voltammogram (b) differential pulse voltammogram of InTPFa in $\mathrm{CH}_{2} \mathrm{Cl}_{2}$ solution containing $0.1 \mathrm{M} \mathrm{TBAPF}_{6}$ at $300 \mathrm{~K}$

Table 3. One electron redox potential data (in $\mathrm{mV}$ ) the fluoroaryl porphyrins in $\mathrm{CH}_{2} \mathrm{Cl}_{2}$ at $300 \mathrm{~K}$

\begin{tabular}{cccc}
\hline \multirow{2}{*}{ Compound } & Oxidation & \multicolumn{2}{c}{ Reduction } \\
\cline { 3 - 4 } & OX1 & RED 1 & RED2 \\
\hline $\mathrm{H}_{2}$ TFPPa & 1055 & -1265 & -1655 \\
$\mathrm{H}_{2}$ TFPPb & 840 & -1360 & -1795 \\
$\mathrm{H}_{2}$ TFPPc & 1210 & -965 & -1225 \\
$\mathrm{H}_{2}$ TFPPd & 895 & -1095 & -1345 \\
InTFPPa & 830 & -1450 & -1840 \\
InTFPPb & 685 & -1555 & -1950 \\
InTFPPc & 980 & -1150 & -1410 \\
InTFPPd & 765 & -1280 & -1525 \\
\hline
\end{tabular}


It is of interest to note that the effect of electron withdrawing group on the reduction potential was more pronounced in the second ring reduction process than the first one in all the $\beta$-nitro substituted (porphyrins c and d). The shift in the ring reduction potentials induced by the presence of electron donating $-\mathrm{N}\left(\mathrm{CH}_{3}\right)_{2}$ groups in the $p$-position of meso- fluoroaryl rings of the free-base porphyrins and its metal(III) derivatives was not significant compared to the shift induced by the introduction of a $-\mathrm{NO}_{2}$ group in the $\beta$-pyrrole position of the porphyrins.

\section{Fluorescence spectra}

Fluorescence emission spectra of In(III) derivatives of the porphyrins are shown in Figure 2. The $S_{1}$ fluoresence spectra of InTFPPc exhibits two emission maxima with $Q(0,0)$ band being more intense than $\mathrm{Q}(0,1)$ band. Interestingly, 2-nitrotetra(pentafluoro) phenyl porphyrinato Indium(III) (InTFPPc) shows two fluorescence bands in $\mathrm{CH}_{2} \mathrm{Cl}_{2}$ solvent with vibrational fine structure unlike to that observed for indium-2-nitrotetra(phenyl/tolyl) porphyrin in the same solvent. It has been observed that Intensity of emission band (InTFPPd) was drastically reduced with the appearance of a featureless emission band. Thus, the In(III) derivative of nitroamino porphyrin undergoes strong fluorescence quenching relative to either amino or nitro substituted porphyrins. These observations suggest that the face-base porphyrin and In(III) derivatives of amino-nitro substituted porphyrins must possess a considerable fraction of charge transfer in the excited state.

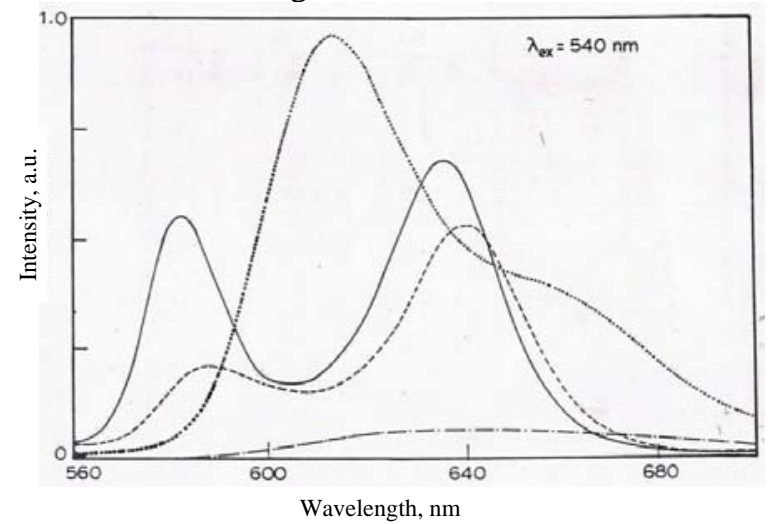

Figure 2. Fluorescene spectra of the In (III) derivatives of the fluoroarylporphyrins in $\mathrm{CH}_{2} \mathrm{Cl}_{2}$ solution at $300 \mathrm{~K}$, a) InTFPPa, InTFPPd, - - - - - (c) In TFPPc,

Table 4. Fluorescene a properties of the porphyrins in $\mathrm{CH}_{2} \mathrm{Cl}_{2}$ at $300 \mathrm{~K}$

\begin{tabular}{ccc}
\hline Compound & $\lambda_{\text {em }}, \mathrm{nm}$ & Relative Q. yield $(\phi)$ \\
\hline $\mathrm{H}_{2}$ TFPPa & 638,702 & 1.0 \\
$\mathrm{H}_{2}$ TFPPb & 654,710 & 0.85 \\
$\mathrm{H}_{2}$ TFPPc & 664,718 & 0.83 \\
$\mathrm{H}_{2}$ TFPPd & 694 & 0.35 \\
$\mathrm{InTFPPa}$ & 584,638 & 1.0 \\
$\mathrm{InTFPPb}$ & 588,642 & 0.79 \\
InTFPPc & 612,652 & 1.2 \\
InTFPPd & 638 & 0.30
\end{tabular}

${ }^{a} \lambda_{\text {em }}$ for free-base and Indium(III) derivatives were 510 and $540 \mathrm{~nm}$ respectively 


\section{References}

1. Kadish K M, Smith K M and Guilar R, The Porphyrin Hand Book, 2000, 14.

2. Egger N G, Motamedi M, Pow Sang M, Osihuela. E and Anderson K T, Pharmacology, 1996, 52(6), 362-370.

3. Nakjima S, Sokaka I and Takemura T, Drug Delivery Syst., 1996, 11, 105.

4. Winkelman J, Rubenfeld S and Mcafee J, J Nucl Med., 1964, 5(6), 462470.

5. Meot Ner M and Alder D A, J Am Chem Soc., 1975, 97(18), 5107-5111; DOI:10.1021/ja00851a014.

6. Cowan J A and Sanders J K M, J Chem Soc Chem Commun., 1985, 1214-1216; DOI:10.1039/C39850001214.

7. Gentemann S, Medforth C J, Forsyth T P, Nurco D J, Smith K M, Fajer J and Holten D, J Am Chem Soc., 1994, 116(16), 7363-7368; DOI:10.1021/ja00095a046.

8. Giraudeau A, Callot H J, Jordon J, Ezhan I and Gross M, J Am Chem Soc., 1979, 101, 3857-3862; DOI:10.1021/ja00508a024.

9. Evan's B, Smith K M and Cavaleiro J A S, J Chem Soc Perkin Trans.,1, 1978, 1, 786.

10. Gong L G and Dolphin D, Can J Chem., 1985, 63(2), 401-405; DOI:10.1139/v85-066.

11. Milgrom L R, J Chem Soc Perkin Trans., 1984, 1, 1483; DOI:10.1039/P19840001483.

12. Gouterman. M, Hall R J, Khalil G E, Martin P C, Shankland E G and Cerny R L, J Am Chem Soc., 1989, 111, 3702-3707; DOI:10.1021/ja00192a030.

13. Bartoli J F, Battioni P, DeFoor W R and Mansuy D, J Chem Soc Chem Commun., 1994, 23-24; DOI:10.1039/C39940000023.

14. Battersby A R and MacDonald E, Porphyrins and Metalloporphyrins,(Ed.) K M Smith (Amsterdam:Elsevier) 1975

15. Morgan B and Dolphin D, Metal Complexes with tetrapyrrole ligands I (Ed.) J W Buchler (Berlin and Heidelberg,Germany:Springer Verlag) 1987.

16. Alder A D, Longo F R, Finarelli J D, Joel Goldmacher, Assour J and Kossakoff L, J Org Chem., 1967, 32, 476-47; DOI:10.1021/jo01288a053. 